\title{
A entrevista com artistas como dispositivo de embate e a disputa discursiva dos anos 1960 e 1970
}

\section{Resumo}

Este artigo propõe uma reflexão sobre a entrevista com artistas como dispositivo de embate na interação de dois sujeitos, tendo em vista que o desejo por apreender trabalhos de arte por suas diversas vias, torna a palavra do artista objeto privilegiado. Algo que pode ser vislumbrado pela compreensão do contexto dos anos 1960/70 quando uma disputa discursiva no campo da arte se dá pela reivindicação dos artistas pelos espaços de fala. A palavra do artista não é uma verdade sobre o trabalho, pois tão determinada histórica, social e culturalmente como ele; assim, a entrevista pode ser compreendida como um mecanismo que abre a produção de sentido e a expande no cruzamento das visões interna e externa de uma prática artística.

\section{Palavras-chave}

Entrevista com artistas. Anos 1960 e 1970. Dispositivo de embate. Produção de sentido. Disputa discursiva. 
1. Digo pelo menos desde Vasari, por ser considerado o primeiro livro de história da arte em que são narradas as vidas dos artistas. VASARI, Giorgio. Vidas dos Artistas. São Paulo: WMF Martins Fontes, 2011.

2. OBRIST, Hans Ulrich. Interviews. Vol. 1. Milan: Edizioni Charta, 2003.

3. GISI, Juliana (Juliana Gisi Martins de Almeida). Fotografia e Práticas Artísticas: os discursos dos artistas nos anos 1960 e 1970. Tese (Doutorado em Artes Visuais). Instituto de Artes da Universidade Federal do Rio Grande do Sul, Porto Alegre, 2013. Em 2014 recebi o XIV Prêmio Marc Ferrez de Fotografia e a transformei em um livro: GISI, Juliana (Juliana Gisi Martins de Almeida). 60/70: as fotografias, os artistas e seus discursos. Curitiba: Juliana Gisi Martins de Almeida, 2015.
Para além das discussões sobre arte cristalizadas nos livros e narrativas históricas, entrar em contato com o pensamento dos artistas é um desejo pulsante no campo do conhecimento artístico; isto, desde, pelo menos, Vasari. ${ }^{1}$ Entender um trabalho de arte pelas suas diversas vias de manifestação tem levado inúmeros pesquisadores a debruçarem-se sobre materiais escritos por artistas. $\mathrm{Na}$ conjunção de elementos biográficos, análises formais, contextualizações históricas, geográficas, culturais, sociais e filosóficas, metáforas, alegorias, comparações tenta-se extrair os sentidos de trabalhos de arte. Nesse contexto, a palavra dos artistas acaba por assumir um papel significativo; como algo que se coloca em paralelo à produção visual, ela assume diferentes lugares dentro dos mais diversos processos de compreensão e aproximação a trabalhos de arte. Um exemplo atual deste interesse é o projeto de Hans Ulrich Olbrist de entrevistas com artistas e outros profissionais. ${ }^{2}$

Essa curiosidade, me parece, está relacionada com a vontade de entender processos e procedimentos, intensões, vontades e projeções do próprio artista sobre seu trabalho, como o lado obscuro da poética; e ainda, com as concepções de arte, pensamentos, questionamentos e problematizações possíveis apenas àqueles e àquelas que se dedicam ao fazer (entendendo o fazer, aqui, em toda a sua gama de possibilidades). Mas a função revelatória que a palavra promete poucas vezes é cumprida, na maioria das vezes, acaba por aumentar os enigmas, acrescentar mais camadas, abrindo o universo de conteúdos, supostamente, latentes. Isso, levando-se em conta que a palavra do artista não é uma verdade sobre o trabalho, mas algo que está em paralelo a ele e, portanto, tão determinada histórica, social e culturalmente como aquele. Assim, problematizar os vários modos de manifestação da palavra do artista acaba por se mostrar um âmbito interessante do pensamento sobre a construção do conhecimento em arte.

Em minha tese de doutorado ${ }^{3}$ me dediquei a estudar textos de artistas, produzidos nos anos 1960 e 1970, reunidos em antologias, com o intuito de destilar, dali, o que os artistas que trabalhavam com fotografia, falavam sobre ela, pensavam, não pensavam, etc. 0 extenso contato com este tipo de material me fez, naquele momento, problematizar estas produções dentro do campo do saber artístico. Uma percepção interessante que adveio da pesquisa com 
as antologias, refere-se ao estatuto da palavra do artista dentro do campo do saber artístico. Até onde pude investigar naquele momento, apesar dos artistas sempre terem escrito (textos, cartas, manifestos, conversas informais, etc.) ${ }^{4}$, é no final da década de 1990 que se inicia um movimento mais intenso de sistematização e disseminação destes materiais, com a exaltação da significância destes para a compreensão da arte. Este movimento pode ser percebido pelo boom de lançamento de antologias de textos de artista $^{5}$, que reverbera o desejo de ampliar e formalizar a integração destes no rol de materiais possíveis para a construção do conhecimento em arte.

A análise que fiz propunha-se a pensar indistintamente os vários modos de materialização da palavra do artista, fossem textos, declarações ou entrevistas, focando na significância destes materiais, o lugar que ocupavam dentro do campo do saber artístico e, especialmente, o modo como os artistas se colocavam na disputa discursiva sobre arte que teve lugar nos anos 1960 e 1970, ou seja, a ocupação do espaço público de reflexão sobre arte. A atenção dada ao discurso dos artistas em minha tese ${ }^{6}$, como meu objeto de estudo, me colocou em contato com inúmeras formas em que este discurso pode ser materializado.

Agora, com a distância da finalização daquele trabalho estabelecida, me proponho a pensar um destes modos: a entrevista. Por um detour, desfoco do conteúdo dos discursos para me dedicar a pensar sua forma, nesse caso a forma particular da entrevista com artistas, além dos contextos em que aconteceram, sua importância, seu foco.

Se eu me pautar pelo material que estudei na época em que elaborei minha pesquisa de doutorado, percebo que nos anos 1960 e 1970 o contexto artístico que abrigou o que hoje chamamos genericamente de arte conceitual foi especialmente propício para a realização e divulgação de entrevistas com artistas.

O processo pelo qual os artistas tomam a palavra naquele momento histórico que Ihes possibilita abrir um espaço na ordem do discurso sobre arte e ser aceitos como sujeitos que podem falar é evidente no tom da disputa que travam com teóricos e críticos. A formação acadêmica desses artistas, cada vez mais generalizada desde aquela época, permite-Ihes adquirir as ferramentas necessárias para ocupar os lugares de quem fala. A força do que disseram e escreveram produziu a instauração do discurso artístico daquele momento. (GISI, 2013, p.28-29) ${ }^{7}$

Mas esta tomada da palavra não é um processo pacífico, ela demanda uma ação que resulte em um tipo de legitimação, algo como uma reestruturação dos lugares de fala dentro de um campo discursivo, pois, como descreve Foucault, os sujeitos que desejam ocupar lugares de fala, de alguma forma, precisam cumprir determinados requisitos:

Creio que existe um terceiro grupo de procedimentos que permitem o controle dos
4. "Alfred Werner, no texto Artists Who Write publicado na revista Art Journal em 1965, aborda, tomando como exemplos os escritos de Gauguin, Van Gogh e Delacroix, a prática escrita de artistas e o processo pelo qual desenvolveu-se uma ideia de que os artistas não são capazes de escrever ou falar sobre arte em geral e seus trabalhos em particular: "Foi somente no último século [dezenove] que emergiu o conceito falso e malicioso de que artistas - pintores, escultores, gravadores - eram anti-intelectuais. Durante a Era da Renascença o artista que escrevia poesia, compunha tratados de problemas estéticos ou manuais de técnica, discursava com acadêmicos sofisticados e viajava amplamente, não era incomum. Um homem da Era Barroca como Rubens falava várias línguas e recebia missões diplomáticas delicadas de seu governo. A Universidade de Cambridge Ihe conferiu o grau honorário de mestre das artes. [...] Delacroix, Gauguin, Van Gogh: seus escritos dissipam a falsa noção de que 'artistas dizem as coisas mais tolas'. Infelizmente, estudantes de História da Arte não são frequentemente solicitados a devotar tanto tempo à leitura de cartas quanto ao exame de pinturas, esculturas e gravuras. Muitos estudantes universitários que obtiveram uma boa ideia de como são as pinturas de Rubens nunca pesquisaram suas cartas (apesar de as correspondências do pintor incluírem proeminentes estudiosos, colecionadores e artistas da época). Os retratos de Sir Joshua Reynolds são mais largamente conhecidos do que os Discursos que ele proferiu na Royal Academy, sem contar as cartas encantadoras que ele endereçou a Lady Ossory. As conversações de Pablo Picasso com Christian Zervos ou os artigos de Henry Moore sobre escultura não são usados com frequência suficiente por escritores de arte contemporânea, muito embora seu valor como pontes para o ego criativo seja imensurável. É verdade que alguns dos maiores artistas do mundo - Giotto, Giorgione, El Greco e Rembrandt vêm logo à mente - ou falharam em deixar para a posteridade uma única carta ou deixaram, no máximo, nada mais que algumas trivialidades que nem iluminam suas personalidades nem lançam luz adicional sobre seu trabalho. É igualmente verdade que um artista às vezes se mostra um 
ARTIGO E ENSAIO

comentador muito fraco de seu próprio trabalho, um expositor muito estranho e inadequado de suas visões. Mas a maioria dos artistas são perfeitos guias através daquelas paisagens desnorteantes que eles criaram. Eles devem ser ouvidos - com ávida atenção!' WERNER, Alfred. Artists Who Write. In: Art Journal, Vol. 24, No 4 (Summer, 1965), p.342-347. College Art Association. Disponivel em http:/l www.jstor.org/stable/774811 acesso 08/11/2012, p.342; 346-7. [Tradução livre da autora].

5. Das antologias de escritos de artista mais conhecidas, existem: CHIPP, H. B. Teorias da Arte Moderna. São Paulo: Martins Fontes, 1996, publicado pela primeira vez em 1968; o livro de Ursula Meyer, Conceptual Art de 1972; o livro de Gregory Battcock Idea Art: a critical anthology de 1973; 0 livro de Lucy Lippard de 1973, republicado em 1997: LIPPARD, Lucy R.. Six years: the dematerialization of the art object from 1966 to 1972... California: University of California Press, 2001. Na década de 1990, são publicados: HARRISON, Charles; WOOD, Paul. Art in Theory 1900-1990: an anthology of changing ideas. Oxford; Massachusetts: Blackwell Publishers Ltd., 1993; STILES, Kristine; SELZ, Peter (Eds.) Theories and Documents of Contemporary Art: a sourcebook of artists' writings. Berkeley; Los Angeles; London: University of California Press, 1996; ALBERRO, Alexander; STIMSON, Blake. Conceptual Art: a critical anthology. London, England: The MIT Press, 1999; OSBORNE, Peter. Conceptual Art. Themes and movements. London: Phaidon Press Limited, 2005, entre outros.

6. Como está posto lá: "Este material não tem a função de ilustrar uma narrativa teórica ou histórica ou exemplificar uma noção: os textos são meu objeto de estudo, foco de meu interesse e esfera na qual se desenvolvem as minhas análises." GISI, 2013, p.33-34.

7. GISI, 2013, p.28-29.

8. FOUCAULT, Michel. A Ordem do Discurso. São Paulo: Edições Loyola, 2008, p.36-37.

9. Sol LeWitt, Paragraphs on Conceptual Art, 1967. In: ALBERRO\&STIMSON, 1999, p.12. [Tradução livre da autora] apud GISI, 2013, p.60, nota 63.

10. Daniel Buren, Beware, 1969: "Alguém pode perguntar porque tantas precauções precisam ser discursos. Desta vez, não se trata de dominar os poderes que eles têm, nem de conjurar os acasos de sua aparição; trata-se de determinar as condições de seu funcionamento, de impor aos indivíduos que os pronunciam certo número de regras e assim de não permitir que todo mundo tenha acesso a eles. Rarefação, desta vez, dos sujeitos que falam; ninguém entrará na ordem do discurso se não satisfizer a certas exigências ou se não for, de início, qualificado para fazê-lo. Mais precisamente: nem todas as regiões do discurso são igualmente abertas e penetráveis; algumas são altamente proibidas (diferenciadas e diferenciantes), enquanto outras parecem quase abertas a todos os ventos e postas, sem restrição prévia, à disposição de cada sujeito que fala. (FOUCAULT, 2008, p.36-37) ${ }^{8}$

Nas regiões mais restritas, só podem penetrar os sujeitos que cumprem certos requisitos e demonstram sua autoridade e qualificação para pronunciar discursos que possam ser acomodados dentro dos limites da disciplina. Naquele momento aparece com mais força o desejo dos artistas tornarem público o que pensam sobre o próprio trabalho, sobre arte e outros assuntos correlatos, em contraposição ao que diziam e escreviam teóricos, críticos e historiadores. E é justamente esta disputa pública que produz a abertura de algumas das regiões deste campo discursivo.

O editor me escreveu que ele é a favor de evitar "a noção de que o artista é um tipo de macaco que tem que ser explicado pelo crítico civilizado". Isto deveria ser uma boa notícia tanto para artistas quanto para macacos. Com esta garantia eu espero justificar a sua confiança. Para continuar uma metáfora do baseball (um artista queria lançar a bola para fora do parque, outro queria ficar relaxado na base e acertar a bola aonde quer que fosse lançada), eu sou grato pela oportunidade de rebater por mim mesmo. (SOL LEWITT,1967 Apud ALBERRO\&STIMSON, 1999, p.12) ${ }^{9}$

Neste excerto do texto Paragraphs on Conceptual Art de Sol Lewitt de 1967, como acontece em muitos outros exemplos ${ }^{10}$, a ironia é uma estratégia para desestabilizar os lugares estabelecidos do discurso que entram em disputa somente quando estes gestos dos artistas começam a problematizá-los. Os questionamentos que encontramos nos textos dos artistas minam a autoridade de críticos e teóricos, questionam sua necessidade e relevância para o campo da arte, reivindicando para si o papel de falar sobre arte e sobre os trabalhos. Seja porque a função dos críticos é anulada por trabalhos que se estruturam a partir da palavra ${ }^{11}$ ou porque os textos dos artistas passam a ser igualmente acessíveis ao público ou porque os artista acreditam que sua visão interna das práticas artísticas é mais significativa que a visão externa dos críticos, teóricos e historiadores.

Juntamente a este processo intenso de reivindicação dos espaços de fala, acontece um movimento de alargamento dos limites do que poderia ser um 
trabalho de arte, o que abriu um espaço para a palavra como elemento constitutivo de práticas artísticas. Como, por exemplo, os trabalhos de Ian Wilson Oral Communication ${ }^{12}$ que, desde 1968 , descrevem a prática de conversar sobre assuntos diversos com pessoas específicas; segundo consta, ele agenda conversas e solicita que não sejam gravadas em nenhuma mídia para que se preserve sua qualidade transiente. Assim como as Dialogue Pieces da Lee Lozano que aconteceram a partir de 1969 e tem uma dinâmica semelhante. A palavra, como a mais diáfana das materializações possíveis de uma prática artística não é acionada exatamente pelo conteúdo do que é dito, nesse caso, mas pela troca que possibilita, pelo engajamento de dois sujeitos em algo que ao fim e ao cabo, não deixa rastros, não pode ser apreendido por terceiros nem comercializado - o que caracteriza um desejo amplamente divulgado por muitos artistas nos anos 1960 e 1970. Algo que está mais próximo de uma performance ou da arte de ação, mas que não é apresentada para um público, mas vivida, experimentada, por duas pessoas, sem derivados, sem resíduos, a não ser aquilo que elas carregam como resultado da vivência.

Essa problematização dos limites do campo da arte, no que se refere à prática artística, pode ser compreendida pelo que chamei de deslocamento do lócus do trabalho de $\operatorname{arte}^{13}$, ou seja, a percepção de que ele pode estar localizado em qualquer uma das várias etapas de uma prática artística: a arte pode estar no próprio fazer ou não ter um objeto definido, além das outras formas de materialização. Esse alargamento, então, abre um campo de indeterminação muito interessante para artistas que estavam, como aconteceu no início do século XX com as vanguardas históricas, questionando convenções e limites do campo da arte. Um movimento de abertura, experimentação, instabilidade; um momento de efervescência e de práticas tão diversas que já não podiam mais ser apreendidas pelas categorias mais tradicionais da teoria, história e crítica de arte e, portanto, demandavam a elaboração e exploração teóricas daqueles que se engajavam nelas. $E$ isso era também o desejo daqueles artistas: participar de conversas e discussões, escrever textos, falar sobre seus trabalhos como uma forma de ampliar sentidos, dar conta de todos os conteúdos que emergiam de tais práticas. Justamente por serem experimentações, a indeterminação fazia parte dos trabalhos de arte e trocar com seus pares deveria parecer um caminho interessante para explorar as possibilidades surgidas com cada proposição, fosse ela materializada como fosse. ${ }^{14}$ Assim, aconteceram muitos encontros, mesas de debates, entrevistas, conversas, dentre outros, entre artistas, as vezes com a participação de teóricos ou críticos ou pensadores da arte; revistas especializadas que publicavam estes materiais abundavam e abriam a interlocução entre estes agentes, muito ativos, do campo da arte..$^{15}$ Artistas aproveitavam as tomadas no lugar de meramente colocar seu trabalho exposto do modo normal, deixando 0 comentário para os 'críticos' e outros colunistas de fofoca profissionais." In: ALBERRO\&STIMSON, 1999, p.155; Victor Burgin, Rules of the Thumb, 1971 "Alguma confusão também emergiu com relação ao que tem sido visto como uma indefinição da distinção entre 'arte' e 'crítica'. Por um lado isto, a bem dizer mediocremente, reconhece o fato de que tanto trabalho quanto comentário usam o mesmo sistema de signos, e por outro lado reconhece a natureza simbiótica das duas atividades." In: ALBERRO\&STIMSON, 1999, p.251; Robert Smithson, Cultural Confinement, 1972: "Um trabalho de arte quando colocado em uma galeria perde sua potência e se torna um objeto portátil ou uma superfície desengajada do mundo externo. Uma sala branca vazia iluminada é ainda uma submissão ao neutro. Trabalhos de arte vistos em tais espaços parecem estar passando por um tipo de convalescência estética. Eles são cuidados como tantos inválidos inanimados, esperando críticos pronunciarem se são curáveis ou incuráveis. A função do curador-diretor é separar arte do resto da sociedade. Em seguida vem a integração. Uma vez que um trabalho de arte fica totalmente neutralizado, ineficaz, abstraído, seguro e politicamente lobotomizado, ele está pronto para ser consumido pela sociedade. Tudo é reduzido a forragem visual e mercadoria transportável. Inovações são permitidas somente se sustentam este tipo de confinamento." In: ALBERRO\&STIMSON, 1999, p.280; Joseph Kosuth, 1975: "O que separa o crítico e historiador da arte do artista é sua demanda por ter uma relação externa com a prática artística; o mito da 'objetividade' científica demandou isso - de alguma forma pode-se definir 0 artista como alguém que tenta afetar mudança do interior, e o historiador/crítico como alguém que tentar afetá-la do exterior. Pode haver pouca dúvida quanto à razão por que 0 historiador/crítico é crescentemente visto como um "policial cultural'." In: ALBERRO\&STIMSON, 1999, p.342; entre outros. [Tradução livre da autora].

11. Como por exemplo o texto Introduction Art\&Language de 1969 do grupo Art and Language que reivindica para si mesmo 0 estatuto de 
trabalho de arte. In: STILES\& SELZ, 1996, p.826-828.

12. Nesta entrada, no livro de Lippard, aparece a descrição de uma entrevista de lan Wilson com Robert Barry, com a gravação da conversa, acredito que este é o motivo pelo qual aparece como uma ação de Barry e não de Wilson. "Robert Barry presents a work by lan Wilson, July, 1970. The work: "Ian Wilson". Ian Wilson and Robert Barry on Oral Communication, July, 1970, Bronx, N.Y.: "[Note: Ian Wilson has been concerned with Oral Communication as a way of making art for the past four years. This part of a discussion between him and Robert Barry was recorded in July, 1970. The interview grew out of the compatibility of the artists' positions at that time and can be considered a part of Robert Barry's 'presentation of artists' series." LIPPARD, 2001, p.179.

13. GISI, 2015, p.114-15.

14. "Mais do que qualquer outra das distintivas qualidades do conceitualismo, então, foi seu intelectualismo que tornou radical e empoderada sua momentânea tomada das instituições da arte. 0 peso do filosofar sem fim sobre 0 significado da arte, o peso da mudança da estética baseada no objeto para um anti-esteticismo baseado na linguagem e na teoria, 0 peso da rejeição do código de rua do happening, do código comercial do pop e do código industrial do minimalismo em favor de associações acadêmicas filosóficas, literárias e científicas, era para usurpar agressivamente a autoridade de interpretar e avaliar arte, presumidamente um domínio privilegiado dos críticos e dos historiadores eruditos. Tal era a liberação em oferta pelo conceitualismo; tal era a insurreição que ele prometia para uma geração de artistas e que the permitiu reivindicar, como Gregory Battcock falou com efusão, que "tudo que aconteceu em 1968, em Columbia e em Paris e em todos os outros lugares simbólicos... REALMENTE significou algo e... realmente vai resultar em algo," porque sua significância já havia se realizado na arte conceitual." STIMSON. In:ALBERRO\&STIMSON, 1999. [Tradução livre da autora]

15. Para se compreender este contexto, é interessante consultar o livro de Lucy Lippard Six Years... c.f.LIPPARD, 2001. chances que tinham para estabelecer interlocuções sobre vários assuntos da arte e da vida e com isso penetravam no campo discursivo da arte.

Desde aquele momento e, talvez, por causa dele, o campo discursivo da arte se transformou e, com ele, o modo de intercâmbio entre os seus agentes. Não que miraculosamente os requisitos para que um sujeito esteja apto a pronunciar discursos no campo da arte tenham sido abandonados, mas, justamente as regras mudaram e novos requisitos se colocaram.

Se retornarmos à discussão sobre o recurso à palavra do artista como caminho, meio ou modo, de aproximação a trabalhos de arte, poéticas e questões mais amplas da arte, podemos estabelecer uma diferenciação entre a entrevista e o texto escrito por um artista como um modo de iniciarmos uma aproximação à especificidade daquela. Um texto escrito por um artista é um dispositivo para veiculação de ideias que parte do, e é desenvolvido como manifestação controlada pelo, artista. E aqui podemos incluir tanto os textos produzidos espontaneamente como aqueles disparados por forças externas (de encomendas à elaboração de projetos). 0 controle exercido pelo artista ao elaborar um texto possibilita a exploração daquelas questões artísticas mais fortes para o próprio artista, na constituição de uma linha de raciocínio que permite que ele passeie pelo seu próprio pensamento, pelo próprio olhar, pelas suas referências mais caras.

Portanto, enquanto um texto é produzido a partir de uma linha determinada pelo artista em que ele concatena suas ideias a partir de uma lógica própria, no seu próprio tempo e, de certa forma, isolado em seu espaço (como qualquer outra pessoa que escreve um texto); a entrevista se realiza por embate, pela troca imediata entre entrevistador e entrevistado, pela conjunção de duas pessoas em diálogo.

Mas a entrevista é um formato textual que pode ser destinado a diversos campos discursivos, de trabalhos acadêmicos à jornais diários, e esta destinação determina o modo como a entrevista é realizada. Nesse sentido, a especificidade da entrevista com artistas pode revelar muito do campo discursivo da arte.

Em uma entrevista acadêmica, geralmente, os entrevistados são selecionados por serem pessoas que tem algo a dizer sobre um assunto, seja ele qual for; mas, apesar de indispensáveis, estes sujeitos são anônimos, ou pelo menos tenta-se garantir o seu anonimato, pois o que interessa é a justaposição de discursos, opiniões, ideias, proposições, quantitativa e/ou qualitativamente. Já em uma entrevista de jornal diário, o que prevalece é o depoimento, seja sobre uma enchente ou um acontecimento político, o que se pretende é ilustrar com este discurso um fato, garante-se ali a assinatura do sujeito responsável pela resposta e ainda sua fotografia, dependendo do caso. Estas características são importantes na medida em que o entrevistado é abordado pelo entrevistador tendo um assunto como foco de atenção, um fato, geralmente, de interesse maior ou que possa refletir-se em um âmbito da vida.

Dentro do espectro da entrevista, ou seja, das suas várias modalidades, as 
entrevistas com artistas se assemelham mais às entrevistas com personalidades. Indagações que se direcionam à compreensão das produções e do processo criativo de um sujeito que ganha notoriedade por sua competência em alguma área do saber, da arte, da ciência, etc.

Mas este preâmbulo tem apenas uma função: estabelecer um modo de olhar para uma interação que carrega uma especificidade. Pois é claro que caracterizar um artista como uma personalidade, no que toca à realização de uma entrevista, informa apenas sobre uma certa reverência, um decoro que determina um lugar ocupado por um sujeito, ou dois, em uma dada situação. Pois que entrevistador e entrevistado, independente da modalidade, estão sempre em embate. A interlocução formalizada pela entrevista obedece a regras implícitas e explícitas, a um desejo de um sujeito que quer saber coisas do outro sujeito e ao estabelecimento de estratégias para que estas coisas sejam reveladas, ou não (depende de qual sujeito estamos falando e da disponibilidade de um ou outro a entregar-se a esta interação).

Nesse sentido, podemos pensar na entrevista como um dispositivo de interação que mobiliza dois sujeitos. $O$ entrevistador, supostamente, conduz a entrevista a partir de um plano prévio; ele, normalmente, quer saber algumas coisas, estuda sobre o artista e seu trabalho, lê textos e entrevistas anteriores (quando eles existem), chega armado com uma agenda de questões artísticas mais relevantes que percebe existirem no trabalho ou poética do entrevistado, ou, ainda polêmicas e questões que sente precisarem ser elucidadas. Mas o entrevistado, muitas vezes, também tem uma agenda de questões e assuntos que o interessam e sobre os quais está disposto a conversar. Nesse sentido, esse dispositivo de interação é também um dispositivo de embate. Pois ambos são instigados a posicionarem-se a partir da fala do outro. Esta característica da entrevista me parece ser o que a torna tão interessante: abrir o espaço de compreensão e conexões, vislumbrar questões que não estavam postas, argumentar sobre temas até então não pontuados, cruzar os pontos de vista externo e interno de uma prática artística. Um mecanismo que abre a produção de sentidos e a expande.

A entrevista de Douglas Huebler realizada por Patricia Norvell em 1969, dentro de um projeto em que ela estava investigando a noção de sistema na arte, deixa clara a relação de embate entre entrevistador e entrevistado:

\section{DOUGLAS HUEBLER:}

Tentar mostrar o sistema, ou a ideia, as coisas que você estabeleceu como a estrutura dentro da qual você vai trabalhar, é disso que trata a arte.

\section{PATRICIA NORVELL:}

Mas então você diz que não importa se as fotos foram tiradas a cada minuto ou a cada cinco dias. 
16. Douglas Huebler, 1969. In: ALBERRO\&NORVELL, 2001, p.148. [Tradução livre da autora]

17. Este assunto é mais longamente discutido ao final do capítulo 3.2 de minha tese de doutorado. Cf. GISI, 2013, p.206216.

\section{DOUGLAS HUEBLER:}

É isso mesmo.

\section{PATRICIA NORVELL:}

Então você está destruindo o seu sistema, ou você o está ignorando?

\section{DOUGLAS HUEBLER:}

Certo, certo, certo. Isso está certo porque, como eu disse, estes sistemas não provam nada também. Ele são sistemas peso-morto [dumbbell]. Sistemas peso-morto muito simples. Em outras palavras...

\section{PATRICIA NORVELL:}

Sim, mas então com o que você deixa o observador ou receptor?

\section{DOUGLAS HUEBLER:}

Você o deixa com a noção de que ele pode ter uma experiência que é apenas aquela experiência. Poderia ser aquela ou a próxima ou a próxima. Em outras palavras, elas estão todas baseadas na convenção que o sistema estabelece. Mas poderia ser qualquer sistema, sabe. E a experiência visual é nocauteada. ${ }^{16}$

Nesse caso, muito interessante, a entrevistadora tenta extrair de Huebler uma 'verdade' com relação aos seus procedimentos de trabalho, por perceber algo como uma inconsistência entre as declarações do artista que, supostamente, descreveriam os passos de realização das suas ações (elementos que, desde o início da década de 1960, fazem parte de seu trabalho), e a efetiva execução dos trabalhos. Mas, como em outros momentos, Huebler se esquiva e joga com a linguagem - o que acontece tanto nas declarações como na conversa com a entrevistadora -, revertendo a ideia de que ele precisaria descrever, nas declarações, linearmente o que fez, em favor de algo que ele percebe como muito mais importante dentro do contexto de sua produção: a experiência possibilitada pela apreensão do trabalho, que envolveria uma reflexão, inclusive, sobre esta veracidade. ${ }^{17}$

$\mathrm{Na}$ entrevista de Jan Dibbets para a Revista Avalanche, as questões colocadas pelos entrevistadores forçam, em algum nível, que Dibbets se posicione sobre algumas questões que eles consideram importantes sobre a relação entre o trabalho e seus resíduos.

\section{AVALANCHE:}

Então, aquilo em que você está realmente interessado são as ideias dentro desse meio. 


\section{JAN DIBBETS:}

Sim, muito mais do que a escala. E a documentação sobre o trabalho também não é de real importância para mim. Já fiz muitos trabalhos sem tirar fotografias.

\section{AVALANCHE:}

Mas algumas pessoas dizem que a fotografia se torna o trabalho, em certo sentido, porque o trabalho é destruído, e a fotografia é o que as pessoas veem.

\section{JAN DIBBETS:}

Bem, eu estou tentando desenvolver algo, e sinto que ainda não estou no final do desenvolvimento.

\section{AVALANCHE:}

Você está tentando desenvolver as ideias mais do que os trabalhos materiais eles mesmos.

\section{JAN DIBBETS:}

Sim, mas eu também sinto que preciso corrigir o que fiz antes. ${ }^{18}$

É possível perceber que os entrevistadores confundem, de certa forma, o trabalho com a documentação, duas produções que estão conectadas, mas são, em termos absolutos, ontologicamente diferentes. O posicionamento de Dibbets é importante porque marca essa diferença, afirmando que o lócus de seu trabaIho está na ideia e, em outro momento da entrevista, na experiência, mas não em sua documentação - mesmo que ao fim seja isso que as pessoas veem... Outro ponto interessante é o modo como Dibbets não tem exatamente certezas, mas está em processo de compreender suas próprias produções na relação com o contexto e modos de materialização de suas ideias. O que é típico de um momento em que os estilhaços da quebra de vários limites dentro do campo da arte reverberam em produções ainda inusitadas, tanto para o público quanto para os artistas que estão experimentando coisas sem prever de antemão todas as suas consequências.

A entrevista de Edward Ruscha, realizada por John Coplans, Concerning "Various Small Fires": Edward Ruscha discusses his perplexing publications, publicada na revista Artforum em fevereiro de 1965, é extremamente instigante, a começar pelo seu título. Em 1965 as publicações de Ruscha configuravam um tipo de experimentação sem precedentes: um livro que continha apenas fotografias, sem texto, e, mais impressionante, cujas fotografias não refletiam a qualidade técnica típica dos livros dos grandes fotógrafos que já estavam estabelecidos no mercado editorial. Por isso a palavra perplexo no título como

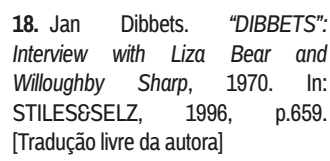

[Tradução livre da autora] 
19. RUSCHA, Edward; COPLANS, John. Concerning "Various Small Fires": Edward Ruscha discusses his perplexing publications, 1965. In: CAMPANY, David. Art and Photography. London; New York: Phaidon Press, 2008, p.223. [Tradução livre da autora] um qualificativo para estas publicações: elas não tinham lugar nem no campo editorial nem no campo da arte (assunto que também é abordado pelos dois artistas na entrevista).

\section{COPLANS:}

Existe alguma correlação entre o modo como você pinta e os livros?

\section{RUSCHA:}

Isso não é importante no que concerne aos livros.

\section{COPLANS:}

Um vez me referi a Twentysix Gasoline Stations e disse que 'ele deveria ser visto como uma pequena pintura' - estava correto?

\section{RUSCHA:}

A única razão seria a relação entre a forma como eu lido com a tipografia na minha pintura. Por exemplo, as vezes intitulo os lados das minhas pinturas na mesma maneira de uma lombada de livro. A similaridade é apenas de estilo. 0 propósito por trás dos livros e das minhas pinturas é completamente diferente. Eu não sei muito bem como meus livros se encaixam. Existe toda uma cena reconhecível em que as pinturas se encaixam. Um dos propósitos do meu livro tem a ver com fazer um objeto produzido em massa. 0 produto final tem um tom muito comercial, profissional. Eu não simpatizo com toda a área de publicações impressas a mão, embora sejam sinceras. Um erro que eu cometi em Twentysix Gasoline Stations foi numerar os livros. Eu estava testando - naquele momento - que cada cópia que uma pessoa pudesse comprar, tivesse um lugar individual na edição. Eu não quero isso agora. ${ }^{19}$

Ruscha já era conhecido por suas pinturas quando publicou seus primeiros livros no início dos anos 1960. Nesse excerto, em que Coplans pergunta sobre uma possível relação entre as duas produções, a primeira reação de Ruscha é rejeitar essa possibilidade, mas não definitivamente. É como se o trânsito fosse vedado na compreensão dos livros mas, talvez não, com relação às pinturas. Isso é muito interessante, pois percebemos no desenvolvimento da segunda resposta, depois da insistência de Coplans, que a reflexão que ele faz sobre os possíveis tangenciamentos o leva a distanciar novamente as duas práticas num balanceamento entre o lugar mais estabelecido das pinturas - dentro de uma tradição mais reconhecível - e o lugar indeterminado dos livros. Uma produção que o mobilizava mas que ele ainda não conseguia abarcar dentro do contexto mais imediato da arte, uma experimentação artística que tensionava os limites do que 
podia ser uma trabalho de arte. Na tentativa de apreender discursivamente os livros, Ruscha o diferencia dos livros em que as fotografias são ampliadas manualmente, como talvez na Camera Work de Stieglitz ${ }^{20}$, afirmando que não haviam, naquele momento, termos de comparação. 0 exercício de abordar seu próprio trabalho, tentando defini-lo, de certa forma, foi provocado por Coplans, outro artista que trabalhava com fotografia. E, por mais que pareça difícil falar sobre algo que aparenta não ter um lastro teórico - ou seja, que possa ser abordado a partir de noções e conceitos já estabelecidos - esse embate produz um tipo de definição, mesmo que aberta, mesmo que feita por negações.

Com estes exemplos podemos pensar a entrevista a partir da noção de dispositivo de embate pontuada acima, uma interação entre sujeitos que jogam com a linguagem em um movimento de produção de discurso, e isso em um sentido amplo. Produção de um discurso sobre arte, uma abertura de suas definições e práticas, um movimento de alcançar um lugar de fala que dê conta daquelas coisas que ainda não estão estabelecidas dentro do campo discursivo da arte, que ainda habitam uma exterioridade selvagem do campo, essa teratologia do saber, aquilo que ainda não foi apaziguado e não está, confortavelmente, estabelecido no verdadeiro. ${ }^{21}$

A palavra do artista não é a verdade sobre seu trabalho, ela é uma fonte incrível de reflexão sobre arte, sobre um tempo, sobre um contexto e sobre o desejo. Este desejo que fundamenta um fazer, uma prática, que coloca em movimento uma ação e resulta, efetivamente, em algo. 0 ímpeto produtivo que se expande para além de intenções e projetos. A fala do artista materializa, enfim, aquilo que sua cegueira Ihe possibilita ver. Como vias diferentes de materialização de concepções e ideias, palavra e trabalho de arte se retroalimentam em movimento constante. Pois que esse lugar muito próprio que o artista ocupa na relação com seu trabalho, lhe abre e veda a visão ao mesmo tempo. Poderíamos até mesmo fazer um paralelo com a elaboração de Marcel Duchamp: “... o 'coeficiente artístico' pessoal é como que uma relação aritmética entre o que permanece inexpresso embora intencionado, e o que é expresso não-intencionalmente." ${ }^{22}$ Nesse sentido, o embate proporcionado pela entrevista, e outras interações assemeIhadas, acrescenta um terceiro elemento a esta equação duchampiana, como se artista e público pudessem estabelecer outro tipo de troca para além do contato imediato com o trabalho.

O desejo de saber o que o artista pensa é o que mobiliza a realização de uma entrevista, como se fosse possível alcançar esse dispositivo interno que põe o artista em funcionamento, como se existisse de fato uma anterioridade absoluta na realização de um trabalho. Mas se pensarmos na discussão de Michel Foucault sobre o autor ${ }^{23}$, perceberemos que esta função é sempre atribuída a posteriori, como um resultado do estabelecimento de uma obra. Ela não existe antes como inteireza e onisciência, como as vezes queremos.
20. Camera Work foi uma revista editada por Alfred Stieglitz de 1903 a 1917 em que as imagens que compunham a revista eram fotogravuras manualmente impressas e cuidadosamente arranjadas entre folhas de papel de seda. Pode-se considerar este 0 exemplo máximo do cuidado e perfeccionismo na elaboração de uma publicação fotográfica. STIEGLITZ, Alfred. Camera Work: the complete illustrations 1903-1917. Köln: Benedikt Taschen Verlag GmbH, 1997.

21. Os termos em itálico foram apropriados da discussão de Michel Foucault sobre a Ordem do Discurso. FOUCAULT, 2008.

22. DUCHAMP, Marcel. O Ato Criador, 1957. In: BATTCOCK, Gregory. A nova Arte. São Paulo: Editora Perspectiva S.A., 1975, p.73.

23. FOUCAULT, Michel. 0 que é um autor? In: MOTTA, Manoel Barros da. (Org.). Michel Foucault. Coleção Ditos e Escritos III Estética: Literatura e Pintura, Música e Cinema. 2a Edição. Rio de Janeiro: Forense Universitária, 2006. 


\section{REFERÊNCIAS}

ALBERRO, Alexander; NORVELL, Patricia [Eds.]. Recording Conceptual Art - early interviews with Barry, Huebler, Kaltenbach, LeWitt, Morris, Oppenheim, Siegelaub, Smithson, Weiner by Patricia Norvell. California: University of California Press, 2001.

ALBERRO, Alexander; STIMSON, Blake. Conceptual Art: a critical anthology. London, England: The MIT Press, 1999.

CAMPANY, David. Art and Photography. London; New York: Phaidon Press, 2008.

CHIPP, H. B. Teorias da Arte Moderna. São Paulo: Martins Fontes, 1996.

HARRISON, Charles; WOOD, Paul. Art in Theory 1900-1990: an anthology of changing ideas. Oxford; Massachusetts: Blackwell Publishers Ltd., 1993.

DUCHAMP, Marcel. O Ato Criador, 1957. In: BATTCOCK, Gregory. A nova Arte. São Paulo: Editora Perspectiva S.A., 1975, p.72.

FOUCAULT, Michel. 0 que é um autor? In: MOTTA, Manoel Barros da. (Org.). Michel Foucault. Coleção Ditos e Escritos III - Estética: Literatura e Pintura, Música e Cinema. 2a Edição. Rio de Janeiro: Forense Universitária, 2006.

FOUCAULT, Michel. A Ordem do Discurso. São Paulo: Edições Loyola, 2008.

GISI, Juliana (Juliana Gisi Martins de Almeida). Fotografia e Práticas Artísticas: os discursos dos artistas nos anos 1960 e 1970. Tese (Doutorado em Artes Visuais). Instituto De Artes da Universidade Federal do Rio Grande do Sul, Porto Alegre, 2013.

GISI, Juliana (Juliana Gisi Martins de Almeida). 60/70: as fotografias, os artistas e seus discursos. Curitiba: Juliana Gisi Martins de Almeida, 2015.
LIPPARD, Lucy R.. Six years: the dematerialization of the art object from 1966 to 1972... California: University of California Press, 2001.

OBRIST, Hans Ulrich. Interviews. Vol. 1. Milan: Edizioni Charta, 2003.

OSBORNE, Peter. Conceptual Art. Themes and movements. London: Phaidon Press Limited, 2005.

STILES, Kristine; SELZ, Peter (Eds.) Theories and Documents of Contemporary Art: a sourcebook of artists' writings. Berkeley; Los Angeles; London: University of California Press, 1996.

STIEGLITZ, Alfred. Camera Work: the complete illustrations 19031917. Köln: Benedikt Taschen Verlag GmbH, 1997.

VASARI, Giorgio. Vidas dos Artistas. São Paulo: WMF Martins Fontes, 2011.

WERNER, Alfred. Artists Who Write. In: Art Journal, Vol. 24, No 4 (Summer, 1965), p.342-347. College Art Association. Disponível em http://www.jstor.org/stable/774811 acesso 08/11/2012.

\section{Juliana Gisi Martins de Almeida}

Professora do Departamento de Teoria e Prática de Ensino do Setor de Educação da Universidade Federal do Paraná, área Artes Visuais. Artista Visual.

(*) Texto enviado em setembro de 2017. 